\title{
HOC VOLVMINE CONTINENTVR
}

Praefatio ab Heiberg conscripta $\ldots \ldots \ldots \ldots \ldots \ldots \ldots$ VI

Additamentum praefationis a Stamatis additum ....... $\mathbf{X}$

Testimonia:

De Euclidis elementorum et vitae memoria ......... XII

De principiorum geometriae memoria $\ldots \ldots \ldots \ldots \ldots . \mathbf{X V I I}$

Indices:

Index rerum geometricarum I et II $\ldots \ldots \ldots \ldots \ldots \ldots . \mathbf{X X X I}$

Index principiorum quibus demonstrationes nituntur... XXXIII

Ordo rerum mathematicarum quae Elementorum libris $1-4$

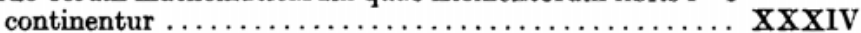

De ratione demonstrandi qua Euclides in Elementis utitur XXXV

Conspectus editionum et librorum $\ldots \ldots \ldots \ldots \ldots \ldots \ldots$ XXXVI

Conspectus abbreviationum ................... XL

Conspectus siglorum et notarum $\ldots \ldots \ldots \ldots \ldots \ldots \ldots$ XLII

Euclidis Elementa

Liber $1 \ldots \ldots \ldots \ldots \ldots \ldots \ldots \ldots \ldots \ldots \ldots \ldots \ldots$

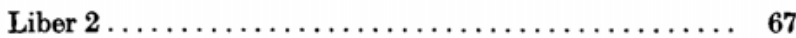

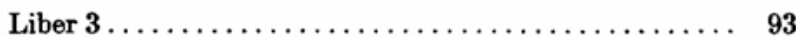

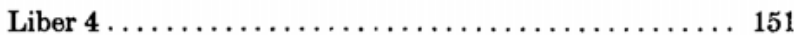

Appendix I: Demonstrationes alterae $\ldots \ldots \ldots \ldots \ldots \ldots 181$

Appendix II : Fragmenta papyracea $\ldots \ldots \ldots \ldots \ldots \ldots 187$ 